\title{
N-phenyl-1-naphthylamine (PNA) Accumulates in Snapping Turtle (Chelydra serpentina) Liver Activating the Detoxification Pathway
}

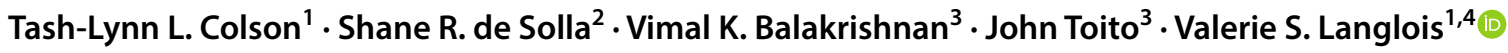

Received: 4 September 2020 / Accepted: 6 November 2020 / Published online: 19 November 2020

(c) The Author(s) 2020

\begin{abstract}
Substituted phenylamine antioxidants (SPAs) are used in Canadian industrial processes. SPAs, specifically N-phenyl-1-naphthylamine (PNA), have received very little attention despite their current use in Canada and their expected aquatic and environmental releases. There is a research gap regarding the effects of PNA in wildlife; therefore, Chelydra serpentina (common snapping turtle) was studied due to its importance as an environmental indicator species. A chronic experiment was performed using PNA spiked food ( 0 to $3446 \mathrm{ng} / \mathrm{g}$ ) to determine its toxicity to juvenile $C$. serpentina. A significant increase in cypla mRNA level was observed in the liver of turtles exposed to $3446 \mathrm{ng} / \mathrm{g}$ PNA, suggesting that phase I detoxification is activated in the exposed animals. Additionally, a significant decrease in cyp $2 b$ transcript level was observed at the two lowest PNA doses, likely indicating another metabolic alteration for PNA. This study helped determine the molecular effects associated with a PNA exposure in reptiles.
\end{abstract}

Keywords Turtle $\cdot$ Toxicity $\cdot$ N-phenyl-1-naphthylamine $\cdot$ Metabolism $\cdot$ Cytochrome P450

Substituted phenylamine antioxidants (SPAs) have been used in a variety of lubricants, dyes, dispersants, and adhesives to protect the product from oxidation. One SPA, N-phenyl-naphthylamine (PNA), is mainly used as an antioxidant in rubber manufacturing and lubricating oils (Wang et al. 1984). PNA is composed of a naphthalene base with a phenyl group connected by an amine group and is considered lipophilic, as its $\log \mathrm{K}_{\mathrm{ow}}$ is 4.2 , and thus it is expected to be slightly bioaccumulative with a bioconcentration factor (BCF) between 50 and 500 (Ozeki and Tejima 1979). Using a fugacity modeling approach, McKay (1991) observed that once PNA is released into the environment, its distribution is predicted to be the following: $36.3 \%$ in soil, $33.9 \%$ in

Valerie S. Langlois

Valerie.Langlois@inrs.ca

1 School of Environmental Studies, Queen's University, Kingston, ON, Canada

2 Ecotoxicology and Wildlife Health Division, Environment and Climate Change Canada, Burlington, ON, Canada

3 Aquatic Contaminants and Research Division, Environment and Climate Change Canada, Burlington, ON, Canada

4 Centre Eau Terre Environnement, Institut national de la recherche scientifique (INRS), 490 de la Couronne, Quebec, QC G1K 9A9, Canada sediment, $28.9 \%$ in water, and $0.016 \%$ in air, suspended sediment, and biota. PNA has been measured in sediment and wastewater at concentrations up to 5 and $7 \mu \mathrm{g} / \mathrm{g}$, respectively (Jungclaus et al. 1978; Lopez-Avila and Hites 1980). More recently, PNA has been measured in biosolids from a wastewater treatment Plant (Hamilton, ON, Canada) at a concentration of $65 \mathrm{ng} / \mathrm{g}$ (Balakrishnan et al. 2016); however, environmental concentration data are limited and outdated. As PNA is currently used in industrial processes in open systems and is potentially bioaccumulative and persistent in the environment, it can be considered as a contaminant of emerging concern. PNA was evaluated as part of the Government of Canada's Chemicals Management Plan, whose purpose is to determine the hazard and risk of chemicals currently used in commerce in Canada. PNA was evaluated as little is known about the environmental exposure, environmental fate, or toxicity of PNA, thus this project was to determine the toxicity to wildlife.

Despite large knowledge gaps of the toxicological significance of PNA, few studies have assessed the effects of this chemical in vertebrates. The majority of the studies on the toxicity of PNA used mammalian models, and the few data that exist on aquatic vertebrates were acute exposures. The $\mathrm{EC}_{50}$ for cell proliferation was determined to be $2 \mathrm{mg} / \mathrm{L}$ for Tetrahymena pyriformis (ciliate) exposed to PNA for 
$48 \mathrm{~h}$ (Epstein et al. 1967). The $\mathrm{LC}_{50}$ was in the range of $0.44-0.74 \mathrm{mg} / \mathrm{L}$ for Oncorhynchus mykiss (rainbow trout) and $0.57-0.82 \mathrm{mg} / \mathrm{L}$ for Lepomis macrochirus (bluegill). More recently, Prosser et al. (2017) determined that the $\mathrm{LC}_{50}$ in Pimephales promelas (fathead minnow) was $74 \mu \mathrm{g} / \mathrm{L}$ and the $\mathrm{EC}_{50}$ for deformities was $95 \mu \mathrm{g} / \mathrm{L}$. The $\mathrm{LC}_{50}$ and $\mathrm{LC}_{100}$ of PNA for Xenopus laevis (African clawed frog) were reported to be $2.3 \mathrm{mg} / \mathrm{L}$ and $5 \mathrm{mg} / \mathrm{L}$ in Lithobates pipiens (Northern leopard frog) (Greenhouse 1976, 1977). Furthermore, development of $L$. pipiens exposed to 20 and $200 \mathrm{mg} / \mathrm{L}$ PNA was halted at Shumway stage 20, in which death resulted afterwards in 100\% of animals (Greenhouse 1976; Shumway 1940). Eye malformations and stunted growth were induced in larval X. laevis exposed to $>5.2 \mathrm{mg} / \mathrm{L}$ PNA, whereas death occurred when treated with concentrations at, or above $6 \mathrm{mg} / \mathrm{L}$ (Greenhouse 1976). All these studies are based upon aqueous exposures, but since PNA is potentially bioaccumulative, dietary exposures may be important. Altogether, these studies suggest that at high exposures of PNA may be a hazard to wildlife, but there is a lack of data on the molecular mechanism of PNA toxicity, most specifically in reptiles.

The goal of this study was to determine if a chronic exposure of PNA in diet to juvenile Chelydra serpentina (snapping turtle) would lead to bioaccumulation and alteration of normal physiological functions, such as detoxification, development, and reproduction. It was hypothesized that PNA will be slightly accumulative to turtles and would alter the expression of a subset of genes related to detoxification and endocrine pathways.

\section{Methods and Materials}

Turtle eggs were collected in June 2014, west of Long Point Provincial Park (ON, CA), a site with few local or known sources of contamination. Eggs were incubated at the Canada Centre for Inland Waters (CCIW at Environment and Climate Change Canada (ECCC), Burlington, ON, CA) until hatched. Collection and housing were performed as described in Colson et al. (2021). The animal care protocol was approved by the Animal Care Committee of Queen's University (Kingston, ON, CA) and followed the guidelines of the Canadian Council of Animal Care.

Trout chow pellets (Martin PROFISHENT ${ }^{\mathrm{TM}}$ ) were treated with PNA (98\%; CAS 90-30-2; TCI Chemicals, Portland, OR, USA) using a rotary evaporator (Buchi Vacobox B-177; Taylor Scientific St. Louis, MO, USA) at CCIW (ECCC). A stock solution of $0.1 \mathrm{mg} / \mathrm{L}$ PNA was made by dissolving PNA into acetone (99.7\% pure, distilled in glass; Caledon Laboratories Ltd., Georgetown, ON). Trout chow was dosed in two batches and placed into the bottom flask with the appropriate volume of stock solution and topped with acetone such that the total volume of the solution was $100 \mathrm{~mL}$. The control food was treated the same way; however, only $100 \mathrm{~mL}$ of unadulterated acetone was added to the flask in place of the PNA solution. After mixing the contaminated pellets they were under a fumehood for $30 \mathrm{~min}$, while being incubated in a waterbath at approximately 30 ${ }^{\circ} \mathrm{C}$. The pressure of the rotary evaporator was initially set at $556 \mathrm{mbar}$, and $\Delta \mathrm{H}$ was set to 1.0 , although the pressure was increased near the end of the evaporation. The food mixture was run for about $1 \mathrm{~h}$, occasionally shaken by hand during this time. The treated trout chow was placed on aluminum foil and let sit in a fume hood for $24 \mathrm{~h}$, stored in plastic containers, and kept frozen at $-20^{\circ} \mathrm{C}$.

Turtle hatchlings $(\mathrm{n}=70)$ were housed in 2.2-L plastic containers with roughly $250 \mathrm{~mL}$ of water to allow turtles to submerge, while still allowing easy access for the turtles to breathe. Turtles $(n=14$ per treatment) were chronicallyexposed to a range of nominal PNA concentrations $(0,0.01$, $0.1,1.0$, and $10 \mu \mathrm{g} / \mathrm{g}$ ) for 81 days. Each hatchling was fed 5 pellets twice a week for the duration of the experiment.

Turtle hatchlings were sacrificed on day 81 of the exposure by decapitation (Colson et al. 2021). Brain, liver, and GMC (gonad-mesonephros complex) were collected, weighed, and immediately placed on dry ice and stored at $-80^{\circ} \mathrm{C}$ until further use. In addition, the whole body was weighed and carapace length was measured for morphometric analyses. Somatic indices were calculated for each collected tissue. Livers were further tested to measure PNA concentrations and mRNA levels.

The extraction and measurement of PNA concentration in turtle liver were performed by liquid chromatographytandem mass spectrometry (LC-MS/MS; (Balakrishnan et al. 2016). Tissue samples ( $0.1 \mathrm{~g}$ dry weight) were spiked using a SPA solution in $\mathrm{MeOH}$ and then evaporated and extracted in $10 \mathrm{~mL}$ acetonitrile using ultrasound assisted extraction. Lipids were removed by gel permeation chromatography in columns packed with $30 \mathrm{~cm}$ of BioBeads (200-400 mesh; BioRad) that were prepared in 50:50 DCM:Hexane (v/v). Extracts were filtered through Allihn funnels through a $10 \mathrm{~cm}$ bed of Celite 545 (Fisher Scientific) on a $1.2 \mu \mathrm{m}$ Whatman GFC filter (VWR Scientific). Nitrogen was used to dry the filtrate to $1 \mathrm{~mL}$. The extracts were then eluted using 50:50 DCM:Hexane $(\mathrm{v} / \mathrm{v})$ in a packed GPC column. Nitrogen was again used to evaporate the DCM:hexane eluate to dryness, after which it was reconstituted in $1 \mathrm{~mL} \mathrm{MeOH}$. Samples were analyzed using a XEVO tandem LC triple quadrupole mass spectrometer (Waters, Milford USA) equipped with a Z-Spray electrospray ionization source and operated in the positive-ion mode. MassLynx software (v. 4.1) was utilized for both data acquisition and processing. Multiple reaction monitoring and selected ion reaction modes were used. Aliquots were injected into an UPLC system (Waters, Milford, MA) with a $2.6 \mu \mathrm{m}$-pore 
size Kinetex C18 column $(2.1 \mathrm{~mm} \times 100 \mathrm{~mm}$; Phenomenex, USA). All PNA concentrations were normalized against the ${ }^{2} \mathrm{H}$-labeled 1,4-benzene- $\mathrm{d}_{4}$-diamine internal standard (internal standard quantification). Total RNA was extracted using TRIzol solution followed by a lithium chloride treatment. DNA contamination was removed by performing DNase I treatment following the manufacturer's protocol (Promega RQ1 RNase-Free DNase kit; Fisher Scientific, Ottawa, ON, CA). Random primers were used to convert RNA to $1 \mu \mathrm{g}$ cDNA using and following Promega GoScript ${ }^{\mathrm{TM}}$ Reverse Transcription System Kit protocol (Madison, WI, USA). The thermocycle program included an annealing temperature of $25^{\circ} \mathrm{C}$ for $5 \mathrm{~min}$, extending temperature of $42^{\circ} \mathrm{C}$ for $60 \mathrm{~min}$, and $15 \mathrm{~min}$ at $70^{\circ} \mathrm{C}$ to inactivate the reverse transcriptase. Samples were kept at $-20^{\circ} \mathrm{C}$ until further use. Eight detoxification-related genes (i.e., ahr, arnt, cypla, cyp2b5, cat, gpxl, sodl, and $h s p 70$ ) were analyzed. Additionally, a subset of thyroid hormone-related genes (dio2, dio3, thro , and thr $\beta$ ) and sex steroid-related genes ( $a r$ and $e s r l$ ) were analyzed to determine potential for endocrine disruption. Primers were either obtained from Colson et al. (2021) or Rhen et al. (2007) (Table 1).

Table 1 Primer design and conditions for genes involved in detoxification, thyroid hormone, and sex steroid pathways in $C$. serpentina

\begin{tabular}{|c|c|c|c|c|c|c|c|}
\hline Function & Gene & $\begin{array}{l}\text { Primer } \\
\text { direc- } \\
\text { tion }\end{array}$ & Sequence $\left(5^{\prime}-3^{\prime}\right)$ & $\begin{array}{l}\text { Annealing } \\
\text { temp }\left({ }^{\circ} \mathrm{C}\right)\end{array}$ & $\begin{array}{l}\text { Ampli- } \\
\text { con size } \\
\text { (bp) }\end{array}$ & $\begin{array}{l}\text { Primer } \\
\text { conc. } \\
(\mu \mathrm{M})\end{array}$ & Reference \\
\hline \multirow[t]{2}{*}{ Normalizing the assay } & \multirow[t]{2}{*}{ odc } & $\mathrm{F}$ & GGAGCTACCCTCAAAACTAGC & \multirow[t]{2}{*}{60} & \multirow[t]{2}{*}{98} & 0.30 & \multirow[t]{26}{*}{ Colson et al. (2021) } \\
\hline & & $\mathrm{R}$ & GTACAGCCACTTCCAACATGG & & & 0.30 & \\
\hline \multirow[t]{16}{*}{$\begin{array}{l}\text { Detoxification path- } \\
\text { way/Oxidative stress }\end{array}$} & \multirow[t]{2}{*}{$a h r$} & $\mathrm{~F}$ & $\begin{array}{l}\text { GCAACACAGAAACCTCTT } \\
\text { ACAG }\end{array}$ & \multirow[t]{2}{*}{58} & \multirow[t]{2}{*}{101} & 0.25 & \\
\hline & & $\mathrm{R}$ & ATACAACACAGCCTCACCAG & & & 0.25 & \\
\hline & \multirow[t]{2}{*}{ arnt } & $\mathrm{F}$ & TCGGATGTTCCCTCTTTGGGT & \multirow[t]{2}{*}{58} & \multirow[t]{2}{*}{110} & 0.25 & \\
\hline & & $\mathrm{R}$ & TCAAGCCCTGGTCGTCTCTT & & & 0.25 & \\
\hline & \multirow[t]{2}{*}{ cat } & $\mathrm{F}$ & CTTGTAGGCAACAACACTCCC & \multirow[t]{2}{*}{60} & \multirow[t]{2}{*}{103} & 0.35 & \\
\hline & & $\mathrm{R}$ & AGATTCAGGACGAAGGCTCC & & & 0.35 & \\
\hline & \multirow[t]{2}{*}{ cypla } & $\mathrm{F}$ & ACACAGGCTTCTTAGTCCCTT & \multirow[t]{2}{*}{58} & \multirow[t]{2}{*}{110} & 0.35 & \\
\hline & & $\mathrm{R}$ & TCAGACAGAAGACAGCAGAGG & & & 0.35 & \\
\hline & \multirow[t]{2}{*}{ cyp $2 b 5$} & $\mathrm{~F}$ & GTGAAGGAAGCCCTGGTGG & \multirow[t]{2}{*}{60} & \multirow[t]{2}{*}{112} & 0.35 & \\
\hline & & $\mathrm{R}$ & CACGTCTCCCCGTTGCTG & & & 0.35 & \\
\hline & \multirow[t]{2}{*}{ hsp70 } & $\mathrm{F}$ & $\begin{array}{l}\text { TGTTGAAGGAAGGACATC } \\
\text { TACCC }\end{array}$ & \multirow[t]{2}{*}{62} & \multirow[t]{2}{*}{185} & 0.35 & \\
\hline & & $\mathrm{R}$ & CССТССАACAATCCCAGCTT & & & 0.35 & \\
\hline & \multirow[t]{2}{*}{ gpxl } & $\mathrm{F}$ & CCTAGGAGAACGCTACCAATG & \multirow[t]{2}{*}{58} & \multirow[t]{2}{*}{140} & 0.35 & \\
\hline & & $\mathrm{R}$ & CAGGAAAGTGAAGAGTGGGTG & & & 0.35 & \\
\hline & \multirow[t]{2}{*}{ sodl } & $\mathrm{F}$ & CTGAAGGAAAACATGGCTTCC & \multirow[t]{2}{*}{62} & \multirow[t]{2}{*}{118} & 0.20 & \\
\hline & & $\mathrm{R}$ & CTCTTTATCCTGTGGTCCACC & & & 0.20 & \\
\hline Thyroid hormone axis & dio2 & $\mathrm{F}$ & GGATGCCTACAAACAGGTCAA & 58 & 115 & 0.35 & \\
\hline & & $\mathrm{R}$ & CTTGGTTCCATATTTCCCGCC & & & 0.35 & \\
\hline & dio3 & $\mathrm{F}$ & CTGAAGGAAAACATGGCTTCC & 58 & 91 & 0.30 & \\
\hline & & $\mathrm{R}$ & CCATGGTGTCCACTGCCAG & & & 0.30 & \\
\hline & thra & $\mathrm{F}$ & $\begin{array}{l}\text { GCAAGGAGGAGATGATCA } \\
\text { AGAC }\end{array}$ & 58 & 104 & 0.35 & \\
\hline & & $\mathrm{R}$ & TTCCGCTTCTGTTTCCA & & & 0.35 & \\
\hline & thrb & $\mathrm{F}$ & CCAGTGCCAGGAATGTCGCTT & 60 & 123 & 0.35 & \\
\hline & & $\mathrm{R}$ & CGTCTCTTCTCTCGGTTTTCT & & & 0.35 & \\
\hline Sex steroid axis & ar & $\mathrm{F}$ & TGGGATGGAGATCTTTCACCAA & 58 & 52 & 0.35 & Rhen et al. (2007) \\
\hline & & $\mathrm{R}$ & GGAGCAAAGTAAAGCATCCGG & & & 0.35 & \\
\hline & esrl & $\mathrm{F}$ & AACCAGTGCACCATCGACAAG & 58 & 103 & 0.20 & \\
\hline & & $\mathrm{R}$ & AATCTTTTCGGATCCCACCTT & & & 0.30 & \\
\hline
\end{tabular}

F: forward primer, R: reverse primer. odc: ornithine decarboxylase, rpl8: ribosomal protein L8, ahr: aryl hydrocarbon receptor, arnt: aryl hydrocarbon receptor nuclear translocator, cat: catalase, cypla: cytochrome P450 1a, cyp2b5: cytochrome P450 2b5, hsp70: heat shock protein $70 \mathrm{kDa}$, gpxl: glutathione peroxidase 1, sod1: superoxide dismutase 1, dio1: iodothyronine deiodinase 1, dio2: iodothyronine deiodinase 1, thra: thyroid hormone receptor alpha, thrb: thyroid hormone receptor beta, ar: androgen receptor, esrl: estrogen receptor 1 
Gene expression analysis was measured on an Agilent Mx3005P Real-Time PCR (qPCR; Agilent Technologies, Inc., Santa Clara, CA, USA) using the Promega GoTaq Bryt ${ }^{\circledR}$ Green qPCR Master Mix (2X; Fisher Scientific). For each qPCR assay, a negative template control and a negative reverse transcriptase control were included to ensure no contamination. A standard curve was prepared through serial dilution (1:4) starting at $50 \mathrm{ng}$. All samples, controls, and the standard curves were run in duplicate. Efficiencies ranged between $83-122 \%$, and coefficients of determination $\left(R^{2}\right)$ were above 0.983 . Gene expression was normalized to the quantified relative expression of $o d c$. Gene expression changes were reported as fold changes relative to the controls.

Statistical analysis of gene expression was done using Prism GraphPad Prism 6 (GraphPad Software Inc, San Diego, CA, USA). Observations that were outside $1.5 \times$ interquartile range (IQR) were removed as outliers prior to analysis and data were transformed $\left(\log _{10}\right.$ or square root) if not normally distributed. Comparisons of gene expression analysis among treatments were performed using a one-way ANOVA followed by Tukey's HSD test. Treatments were considered significantly different if $p$-values were equal to, or below 0.05 .

\section{Results and Discussion}

PNA concentrations were measured in food pellets to determine the actual dose given to $C$. serpentina. Mean concentrations in liver for each treatment were $0.02,0.54,0.05$, 0.55 , and $7.62 \mu \mathrm{g} / \mathrm{g}$, dry weight when exposed to pellets of $0,4,38,964$, and 3,446 $\mu \mathrm{g} / \mathrm{g}$, dry weight PNA, respectively (Fig. 1). A significant increase was observed in PNA concentrations in liver $\left(\mathrm{R}^{2}: 0.78\right.$; Fig. 1). Livers from the two highest treatments accumulated significantly more PNA than the control $(0.55$ and $7.62 \mu \mathrm{g} / \mathrm{g}$ compared to $0.02 \mu \mathrm{g} / \mathrm{g}$, respectively). In addition, the liver accumulation factors (liver concentration/concentration in food) calculated for the two highest treatments were 0.006 and 0.0023 in liver, respectively.

A range of morphometric measurements were taken at experiment completion to assess if PNA altered growth in juvenile $C$. serpentina. Body mass ranged between 9.2 and $19.2 \mathrm{~g}$, while carapace length ranged from 3.2 to $4.1 \mathrm{~cm}$ across treatments, with averages of $13.6 \mathrm{~g}$ and $3.7 \mathrm{~cm}$, respectively. The gonadosomatic index (GSI) ranged from 0.07 to 0.56 with an average of 0.28 . The mean GSI was significantly larger in the highest PNA treatment $(3446 \mu \mathrm{g} / \mathrm{g}$ PNA) when compared to that of controls which suggests that PNA exposure can increase gonadal mass. Mahboob and Sheri (2002) have determined that the GSI is a good indicator of gonadal enzymatic activity. However, given the lack

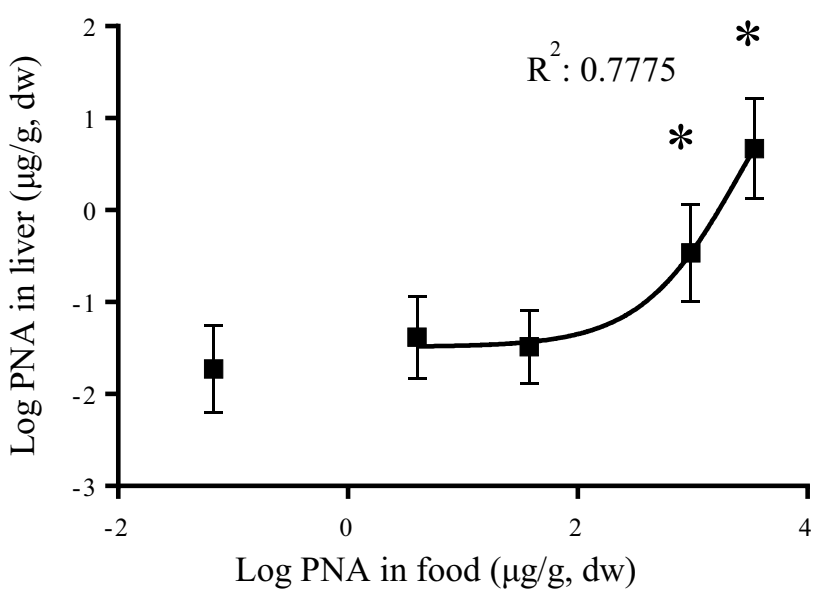

Fig. 1 PNA accumulation in the $C$. serpentina liver exposed to varying concentrations $(0-3,446 \mu \mathrm{g} / \mathrm{g}$ PNA, dw) after 81 days. Data is presented as mean $(n=7-9) \pm$ SD. A significant sigmoidal increase was noted $\mathrm{p}<0.05$ and denoted by an asterisk (*) after a one-way ANOVA

of research on PNA or related SPAs, no other studies have reported any change in GSI or gonad mass so far. Therefore, the present study suggests that PNA can increase gonadal growth; however, due to the lack of expression changes in ar or esrl mRNA levels, the observed gonadal growth was unlikely mediated through differential androgen- or estrogen-receptor mRNA expression. Further research would be required to investigate this increase in gonadal mass. No other significant differences were found for any other morphometric endpoints.

Fourteen genes were targeted to assess detoxification, oxidative stress-, thyroid hormone-, and reproductive-related pathways. A significant 2.7-fold increase $(p=0.0003)$ in cypla mRNA level was observed after exposure to $3,446 \mu \mathrm{g} / \mathrm{g}$ PNA (Fig. 2a). This may indicate that PNA can be detoxified through phase I metabolism. CYP1A is the enzyme responsible for the addition of hydroxyl groups during xenobiotic metabolism. This increase in cypla expression in $C$. serpentina suggests that PNA may be metabolized through hydroxylation in the turtle liver. For example, hydroxylated metabolites of PNA were detected in rat microsomes following in vitro exposure (Xuanxian and Wolff 1992). Taken together, the increase in cypla mRNA level measured in this study and the susceptibility of PNA to be metabolized into hydroxylated metabolites, suggest that PNA is likely metabolized in the liver via the CYP1A pathway.

In contrast, significant 0.5 - and 0.4 -fold decreases $(p=0.0084)$ were observed in cyp $2 b 5$ transcript level after exposure to 4 and $38 \mu \mathrm{g} / \mathrm{g}$ PNA, respectively (Fig. 2b). No other changes in gene expression were observed. Most interestingly, a U-shaped response was observed for 
Fig. 2 Cytochrome P450 gene expression in $C$. serpentina liver after exposure to 0 (gray box) and 4-3446 (black boxes) $\mu \mathrm{g} / \mathrm{g}$ PNA. Data are presented as mean fold change + SEM. Significance $(\mathrm{p}<0.05)$ compared to control is depicted by an asterisk (*) after a one-way ANOVA and Tukey's test. cypla $=$ cytochrome $\mathrm{P} 4501 \mathrm{~A}$; cyp 2 b5 = cytochrome $\mathrm{P} 450$ 2B5 a) cyp1a

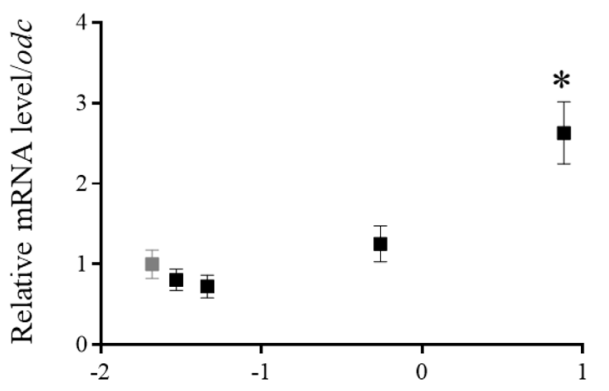

b) cyp $2 b 5$

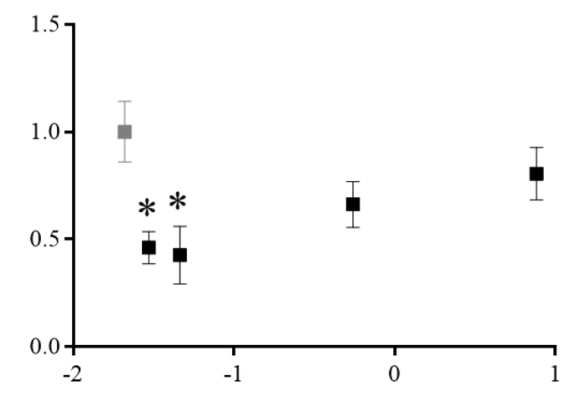

Log mean PNA in liver $(\mu \mathrm{g} / \mathrm{g}, \mathrm{dw})$

cyp $2 b 5$ transcript level with initial decreases in cyp $2 b 5$ mRNA levels at low doses and then a return to control levels at higher doses, which suggests a hormetic response. Hormesis is a dose-response relationship in which the response resembles a U-shape or an inverted U-shape due to stimulation at low doses but inhibition at high doses (Davis and Svendsgaard 1990). Many underlying mechanisms may be responsible for hormesis, such as an overcompensation to maintain homeostasis at low doses of a toxicant (Calabrese and Baldwin 2001). For example, exposure to dioxin-like compounds can create a U-shape response at low doses, which coincides with the multiple different effects of dioxins, such as cell proliferation, toxicity, and mitosuppression for tumour induction (Andersen and Barton 1998). Further investigation would be needed to validate and explain the inverted U-shaped response measured for cyp $2 b 5$ in $C$. serpentina livers.

Despite the alterations observed for the expression of the two cyp genes analyzed, no other changes were noted for any of the phase II detoxification- or oxidative stressrelated genes investigated. This can be partly explained by the turtle's high tolerance to oxidative stress. $C$. serpentina are known to have high basal antioxidant defenses (i.e., CAT, SOD, and GST) (Hermes-Lima and ZentenoSavin 2002). This high level of antioxidants allows turtles to resist long periods of stress, such as hibernation, in which they undergo anoxia (Storey 1996), in which reactive oxygen species are generated during periods of high oxygen tension during reoxygenation (Krivoruchko and Storey 2010).

This is the first study to determine if PNA is toxic to reptiles, and more specifically, in turtles. Overall, our data have shown that PNA accumulates, albeit slightly, in the turtle liver and suggests that it can be likely metabolized by P450 enzymes. Further investigation is needed to understand the exact detoxification mechanisms of PNA in juvenile turtles. Understanding how emerging contaminants, such as PNA, can affect wildlife is imperative to assist environmental risk assessment to prevent negative health consequences to wildlife populations.

Acknowledgements The authors would like to thank Kyna Intini, Kim McCormack, Kimberly O'Hare and Sara Witzke of ECCC for turtle egg collection and Sarah Wallace and Christina Emerton (RMC) for their help with exposures, animal care, and sampling. Funding was provided by Ecotoxicology and Wildlife Health Division (ECCC) to SdS and Canada Research Chair (CRC) to VSL.

Author Contributions Conceptualization and Methodology, T-LLC, SRdS, and VSL; Investigation, T-LLC, VKB and JT; Writing-Original Draft, T-LLC; Writing—Review \& Editing, T-LLC, SRdS, VKB, JT, and VSL; Funding Acquisition, SRdS and VSL; Resources, SRdS, and VSL; Supervision, SRdS and VSL.

\section{Compliance with Etical Standards}

Conflict of interest The authors have no conflicts of interest to declare.

Open Access This article is licensed under a Creative Commons Attribution 4.0 International License, which permits use, sharing, adaptation, distribution and reproduction in any medium or format, as long as you give appropriate credit to the original author(s) and the source, provide a link to the Creative Commons licence, and indicate if changes were made. The images or other third party material in this article are included in the article's Creative Commons licence, unless indicated otherwise in a credit line to the material. If material is not included in the article's Creative Commons licence and your intended use is not permitted by statutory regulation or exceeds the permitted use, you will need to obtain permission directly from the copyright holder. To view a copy of this licence, visit http://creativecommons.org/licenses/by/4.0/.

\section{References}

Andersen ME, Barton HA (1998) The use of biochemical and molecular parameters to estimate dose-response relationships at low levels of exposure. Environ Health Perspect 106:349-355. https ://doi.org/10.1289/ehp.98106s 1349

Balakrishnan V et al (2016) Chemicals management plan progress report: the environmental fate, distribution and effects of substituted phenylamine antioxidants (SPAs). Developing analytical 
methods, investgiating toxicity and evaluating bioaccumlation final report to science and Ri. Ottawa, ON, Canada

Calabrese EJ, Baldwin LA (2001) Hormesis: U-shaped dose responses and their centrality in toxicology. Trends Pharmacol Sci 22:285291. https://doi.org/10.1016/S0165-6147(00)01719-3

Colson TLL, de Solla SR, Langlois VS (2021) Bioaccumulation and physiological responses of the turtle Chelydra serpentina exposed to polychlorinated biphenyls during early life stages. Chemosphere 263:128146

Davis JM, Svendsgaard DJ (1990) U-Shaped dose-response curves: their occurrence and implications for risk assessment. J Toxicol Environ Health 30:71-83. https://doi.org/10.1080/1528739900 9531412

Epstein SS, Saporoschetz IB, Hutner S (1967) Toxicity of antioxidants to Tetrahymena pyriformis. J Protozool 14:238-244

Greenhouse G (1976) Effects of pollutants on eggs, embryos and larvae of amphibian. The regents of the University of California

Greenhouse G (1977) Toxicity of N-phenyl-alpha-naphthylamine and hydrazine to Xenopus laevis embryos and larvae. Bull Environ Contam Toxicol 18:503-511

Hermes-Lima M, Zenteno-Savin T (2002) Animal response to drastic changes in oxygen availability and physiological oxidative stress. Comp Biochem Physiol C Toxicol Pharmacol 133:537-556. https ://doi.org/10.1016/S1532-0456(02)00080-7

Jungclaus GA, Lopez-Avila V, Hites RA (1978) Organic compounds in an industrial wastewater: a case study of their environmental impact. Environ Sci Technol 12:88-96

Krivoruchko A, Storey KB (2010) Regulation of the heat shock response under anoxia in the turtle, Trachemys scripta elegans. J Comp Physiol B 180:403-414. https://doi.org/10.1007/s0036 0-009-0414-9

Lopez-Avila V, Hites RA (1980) Organic compounds in an industrial wastewater. their transport into sediments. Environ Sci Technol 14:1382-1390. https://doi.org/10.1021/es60171a007
Mackay D (2002) Multimedia models: the fugacity approach, 1st ed. Lewis Publishers, 1991

Mahboob S, Sheri AN (2002) Relationships among gonad weight, liver weight and body weight of major, common and some Chinese carps under composite culture system with special reference to pond fertilization. J Anim Sci 15:740-744

Ozeki S, Tejima K (1979) Drug Interactions. V. Binding of basic compounds to bovine serum albumin by fluorescent probe technique. Chem Pharm Bull 27:368-646

Prosser RS et al (2017) Toxicity of sediment-associated substituted phenylamine antioxidants on the early life stages of Pimephales promelas and a characterization of effects on freshwater organisms. Environ Toxicol Chem 36:2730-2738. https://doi. org/10.1002/etc. 3828

Rhen T, Metzger K, Schroeder A, Woodward R (2007) Expression of putative sex-determining genes during the thermosensitive period of gonad development in the snapping turtle, Chelydra serpentina. Sex Dev 1:255-270. https://doi.org/10.1159/000104775

Shumway W (1940) Stage in the normal development of Rana pipiens. Anat Rec 78:138-147

Storey KB (1996) Oxidative stress: animal adaptations in nature. Braz J Med Biol Res 29:1715-1733

Wang H, Wang D, Dzeng R (1984) Carcinogenicity of N-phenyl1-naphthylamine and N-phenyl-2-naphthylamine in mice. Cancer Res 44:3098-3101

Xuanxian X, Wolff T (1992) Metabolism of N-phenyl-2-naphthylamine and N-phenyl-1-naphthylamine by rat hepatic microsomes and hepatocytes. J Environ Sci (China) 4:74-83

Publisher's Note Springer Nature remains neutral with regard to jurisdictional claims in published maps and institutional affiliations. 